\title{
SPONTANEOUS ADVERSE DRUG REACTION REPORTING IN A TERTIARY CARE HOSPITAL IN CALICUT
}

\author{
SIRAJ SUNDARAN ${ }^{1 *}$, ABHIJITH P ${ }^{1}{ }^{1}$, ALEENA ALEX ${ }^{1}$, AMRUTHA KRISHNAN ${ }^{1}$, ANGEL TISA JACOB ${ }^{1}$, G BABU ${ }^{1}$, \\ SUDEEP BALAKRISHNAN ${ }^{2}$
}

${ }^{1}$ Department of Pharmacy Practice, Devaki Amma Memorial College of Pharmacy, Malappuram, South India. ${ }^{2}$ Department of Neurology, PVS Hospital (P) Ltd, Calicut, South India. Email: tsirajsundaran@gmail.com

\author{
Received: 11 January 2018, Revised and Accepted: 09 May 2018
}

ABSTRACT

Objective: The study was conducted to assess the adverse drug reactions (ADRs) reported in a tertiary care hospital in Calicut.

Methods: Spontaneous ADR reporting method was followed for the study. The ADRs reported by the health-care professionals, or the patients were confirmed with the physician-in-charge. Further, the assessments of type, severity, and preventability of reported ADRs were done using Wills and Brown classification, modified Schumock and Thornton severity scale, and modified Hartwig and Siegel preventability scale.

Results: A total of 30 ADRs were reported. A study found that the incidence of ADRs was more in males (1.14\%) when compared to females (0.79\%). Geriatric patients showed more incidences of ADRs (1.04\%) when compared to pediatrics (0.69\%) and adults (1.02\%). More number of ADRs was associated with antibiotics (23.33\%) and anticonvulsants (23.33\%) than another category of drugs. Based on type or mechanism involved $80 \%$ of ADRs were pharmacologically related (Augmented) ADRs. Severity assessment showed that 50\% were mild, 46.67\% were moderate, and 3.33\% were severe. Assessment of preventability showed that $63.33 \%$ of ADRs were not preventable, $30 \%$ were preventable, and $6.67 \%$ were probably preventable.

Conclusion: The study was useful in finding the age category and drugs that were more prone to ADRs. This will render precautions and monitoring in the future. The importance of ADR monitoring unit and aid of clinical pharmacist in the monitoring and assessment were very well considered during the study.

Keywords: Adverse drug reaction, Spontaneous reporting, Type, Severity, Preventability.

(C) 2018 The Authors. Published by Innovare Academic Sciences Pvt Ltd. This is an open access article under the CC BY license (http://creativecommons. org/licenses/by/4. 0/) DOI: http://dx.doi.org/10.22159/ajpcr.2018.v11i8.26026

\section{INTRODUCTION}

The World Health Organization defines an adverse drug reaction (ADR) as any response to a drug which is noxious, unintended and occurs at doses normally used in men for prophylaxis, diagnosis, or therapy of disease or for the modification of physiologic function. This definition excludes accidental or intentional drug abuse, treatment failure, and administration errors [1]. Every medication has potential adverse or side effects, also many medications have potential interactions with other substances. To prevent these types of adverse effects, the health-care practitioners should select and prescribe the best and safest medicines according to the medical needs of the patients [17]. Efficacy and safety are the two major concerns of drug, where the efficacy of drug can be quantified with relative ease, but the same cannot be done for safety.

Epidemiological studies have estimated ADRs to be the fourth to sixth leading cause of death [14]. It has been estimated that approximately $2.9-5 \%$ of all hospital admissions are caused by ADRs and as many as $35 \%$ of hospitalized patients experience an ADR during their hospital stay. Serious ADRs account for $6.7 \%$ of all hospital admissions. ADRs have an economic burden on the patients as well as on the health-care establishment [2]. In India, a study concluded that $9.8 \%$ incidence of ADRs, of which $3.4 \%$ of ADRs were associated with hospital admission [14]. Another study concluded that admissions due to ADRs accounted for $0.7 \%$ of the total admissions and the deaths due to ADR accounted for $1.8 \%$ of total ADRs. At present, tracking of ADRs is mandated by the regulatory agencies. Due to lack of reporting, the real effects of ADRs are difficult to estimate. Hospital-based ADRs monitoring and reporting programs can identify and quantify the risks associated with the use of drugs and are useful in identifying and minimizing preventable ADRs. This study here had various assessments for monitoring ADRs which was not previously done in the hospital. The study was an approach to provide the hospital with a fully-fledged ADR monitoring program by the clinical pharmacy division.

The objectives of this study were to assess the type of ADRs reported in the hospital and determined its severity and preventability.

\section{METHODS}

This prospective spontaneous ADR reporting study was conducted in the inpatient wards of PVS Hospital (P) Ltd., Calicut, for 7 months (October 2016-April 2017). The study was conducted after attaining approval from the institutional ethics committee of the hospital. Medical professionals were provided with the awareness on ADR monitoring and reporting. Each day the patients were interviewed and checked for the occurrence of any ADRs. The ADRs reported by the health-care professionals and/ or patients were confirmed with the help of physician-in-charge. Further, the reported ADRs were assessed for the type based on Wills and Brown classification, preventability using modified Schumock and Thornton scale, and severity using modified Hartwig and Siegel scale. Statistical analysis was performed using Chi-square test and SPSS software 4 windows version 20 was used for the analysis.

\section{RESULTS}

Demographic characteristics

ADR was found in a total of 30 patients among 3074 inpatient admissions during the study period. The incidence rate was found to be $1.95 \%$. The demographic characteristics of the patients are represented 
in Table 1. Incidence rate was found to be more for the male patients when compared to the female patients, although the findings did not show any statistical significance. The tertiary references such as clinical and medical textbooks and some journals supported the fact that females were more prone to ADRs, but our findings showed difference.

The study showed higher incidence in case of geriatrics followed by adults and pediatrics, respectively. This may be because the number of hospital admissions of geriatrics was more compared to the other two age groups, and pediatricians tend to limit the number of drugs in their patients.

Among ADRs reported, 23.33\% were associated with antibiotics and anticonvulsants followed by antihypertensives (20\%). Therapeutic classifications of drugs associated with ADRs are represented in Table 2.

\section{Assessments of ADRs}

Wills and Brown classification was used to categorize the ADRs based on the reason or mechanism. It was found that $24(80 \%)$ of the ADRs reported were type A (augmented) or pharmacological reaction followed by 5 (16.67\%) type $\mathrm{H}$ (hypersensitivity) reaction and $1(3.33 \%)$ type $\mathrm{C}$ (chemical reaction)

Modified Hartwig and Siegel severity scale was used for the assessment of severity. Among the 30 ADRs, 15 (50\%) were mild, 14 (46.67\%) were moderate, and $1(3.33 \%)$ was severe. The severity subcategorizations are represented in Fig. 1.

Modified Schumock and Thornton scale was used for the preventability assessment of the reported ADRs. Here, 19 (63.33\%) of the ADRs were found to be not preventable, $9(30 \%)$ of the ADRs were found to be preventable, and $2(6.67 \%)$ of the ADRs were found to be probably

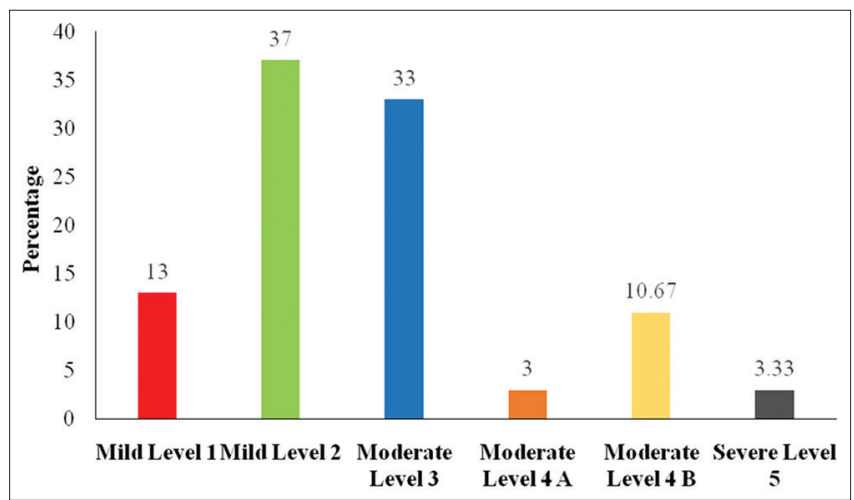

Fig. 1: Severity of the adverse drug reactions

Table 1: Demographic details

\begin{tabular}{llll}
\hline Characteristics & Number of patients with ADR & Number of inpatients & incidence rate (\%) \\
\hline Gender & 18 & 1572 & 1.14 \\
$\quad$ Male & 12 & 1502 & 0.79 \\
$\quad$ Female & 4 & 573 & 0.69 \\
Age group & 11 & 1069 & 1.02 \\
$\quad$ Pediatrics & 15 & 1432 & 0.754 \\
$\quad$ Adult & & & 1.04 \\
$\quad$ Geriatrics & & & \\
\hline
\end{tabular}

ADRs: Adverse drug reactions

Table 2: Drug class associated with ADRs

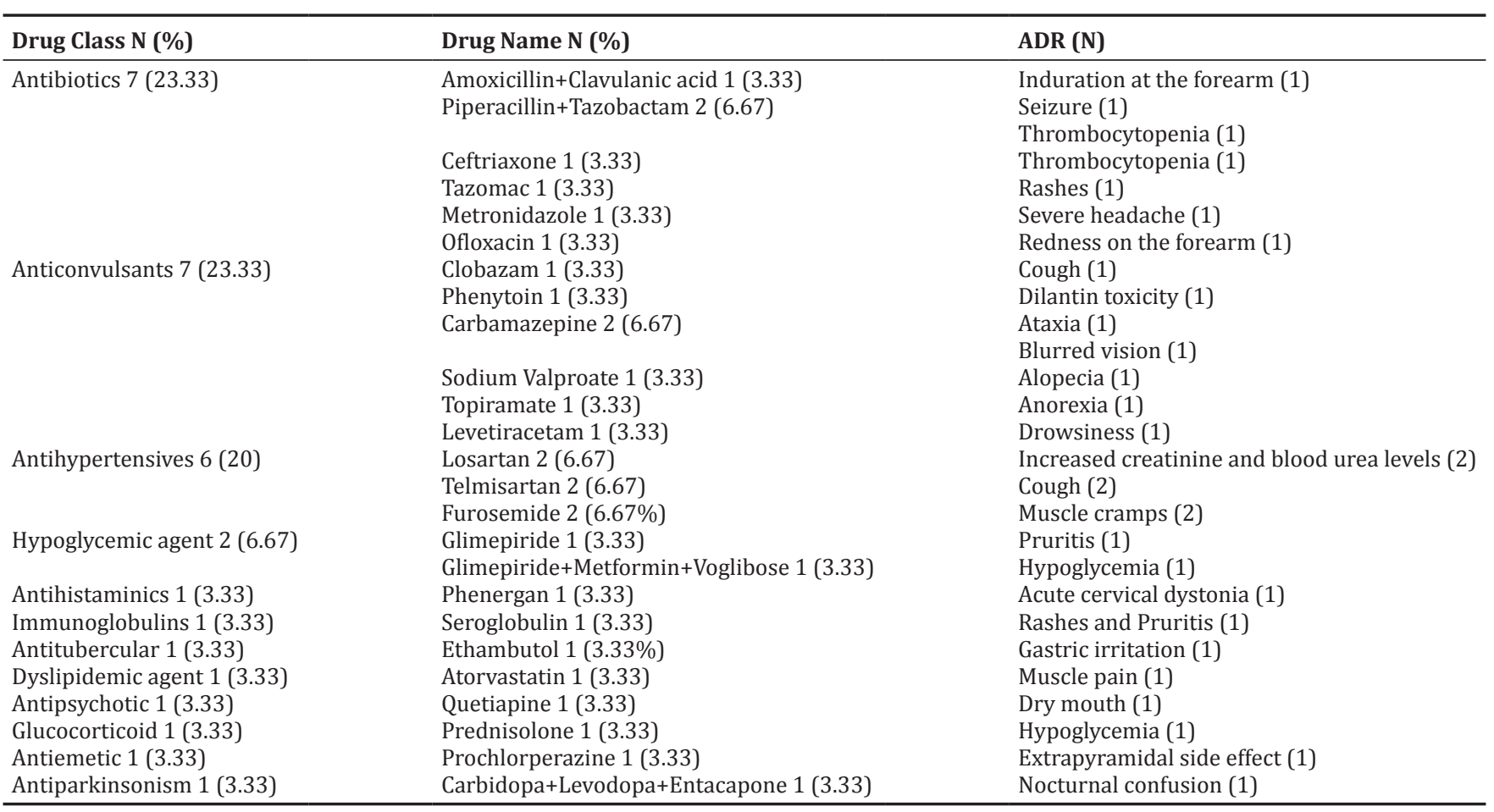

ADRs: Adverse drug reactions 
preventable. It may be difficult to prevent all the ADRs; however, it is possible for the future precautions.

\section{DISCUSSION}

The study shows that incidence rate of ADRs was found to be more for males when compared to females. Our findings were similar to the study conducted by Devang Ashwinkumar Rana et al. [3] and Dilip et al. [4]. The study also showed that the incidence rate for geriatrics to be higher than adults and pediatrics. This could be due to the increased hospital admissions of geriatric patients. These findings were consistent with the study carried out by Shamna et al. [5] and Prudhivi Ramakrishna et al. [6]

Our study found that antibiotics and anticonvulsants were the class of drugs more prone to ADRs. One possible reason could be the wide usage of antibiotics in our study site and more reporting from the neurology department. These findings were similar to the study findings of Raut et al. [7]. The study found that $80 \%$ of the ADRs reported were type A reaction or pharmacological reaction followed by $16.67 \%$ of type $\mathrm{H}$ (hypersensitivity) reaction and $3.33 \%$ of type $\mathrm{C}$ (chemical reaction). These findings were similar to the study result found by Surjeet and Wafai [8]. Hypersensitivity reactions are easily detected, whereas other types need a regular monitoring by the health-care professionals. Most of the ADRs were found to be mild and findings had similarity to the study by S. Ponnusankar et al. [9]. Majority of the ADRs were not preventable (63.33\%). These findings on preventability showed similarity to the study by Mandavi et al. [10]. The preventability assessment can help in minimizing the ADRs or taking proper precautionary measures in future with the same or similar drugs.

\section{CONCLUSION}

ADRs are inevitable risk factor associated with the use of medicines. However, careful attention to dosage, age, and renal function can minimize the risk of developing ADRs in many patients. The study came across age, gender, drug class, causality assessments, severity, and preventability. The study found the age group and common drugs that are more prone to ADRs. The clinical pharmacist can take precautions in the future on these aspects and try to adopt the best measures to minimize or avoid ADRs. To minimize the problem associated with ADRs, it is advisable that every hospital should have pharmacovigilance centers involving clinical pharmacist services that can provide the most for the assessment and reporting.

\section{AUTHOR'S CONTRIBUTION}

Dr. Siraj Sundaran has provided the design, intellectual content, innovations, and protocol for conducting the study along with mentorship.

Mr. Abhijith P S, Ms. Aleena Alex, Ms. Amrutha Krishnan, and Ms. Angel Tisa Jacob have involved with the ADR reporting and data processing.

Dr. Sudeep Balakrishnan has involved with the advisory and monitoring of the study.

\section{CONFLICTS OF INTEREST}

The authors of this study declare that there are no conflicts of interest regarding the publication of this article.

\section{FINANCIAL SUPPORT AND SPONSORSHIP}

Nil.

\section{REFERENCES}

1. World Health Organizations. A Guide to Detecting and Reporting Adverse Drug Reactions. Safety of Medicines. Geneva: World Health Organizations; 2002.

2. Swamy S, Bhanuprakash NP, Muralimohan SM. Profile of suspected adverse drug reaction in teaching tertiary care hospital. J Pharmacol Clin Toxicol 2013;1:1005.

3. Rana DA, Bhadiyadara SN, Shah HJ, Malhotra S, Pal VJ. Consistency between causality assessments obtained with various scales and their agreement for adverse drug events reported in paediatric population. J Young Pharm 2015;7:89-95.

4. Dilip C, Lisa MM, Saraswathi R, Divya R. Adverse drug reaction monitoring in a tertiary level referral hospital, Kerala. Indian J Pharm Pract 2012;5:28-32.

5. Shamna M, Dilip C, Ajmal M, Mohan L, Shinu C, Jafer CP, et al. A prospective study on adverse drug reactions of antibiotics in a tertiary care hospital. Saudi Pharm J 2014;22:303-8.

6. Ramakrishna P, Barman AK, Mahanda PJ, Lahkar M, Ramaiah M. Collection, detection, assessment, monitoring and prevention of adverse drug reactions in the nephrology department of guwahati medical college and hospital, Assam, India. Glob J 2014;14:29-31.

7. Raut A, Pawar A, Pankaj M, Srivastava P, Mishra A. Clinical pattern and severity of cutaneous adverse drug reaction. Int J Pharm Pharm Sci 2013;5:612-6.

8. Surjeet S, Wafai ZA. Adverse drug reaction monitoring at tertiary care hospital S.K.I.M.S. Srinagar. JK Pract 2012;17:58-63.

9. Ponnusankar S, Tejaswini M, Chaitanya M. Assessment of adverse drug reaction based on spontaneous signals at secondary care public hospital. Indian J Pharm Sci 2015;7:490-3.

10. Mandavi K, D' Cruz S, Sachdev A, Tiwari P. Adverse drug reaction and their risk factors among Indian ambulatory elderly patient. Indian J Med Res 2012;136:404-10.

11. Jose J, Rao PG. Pattern of adverse drug reactions notified by spontaneous reporting in a tertiary care teaching hospital. Pharmacol Res 2006;54:226-33.

12. Padmaja SY, Palanisamy S. A study on assessment, monitoring and documentation of adverse drug reactions. Int J Pharm Teach Pract 2012;3:253-6.

13. Adepu R, Srikanth MS. Adverse drug reaction monitoring and reporting by community pharmacists. World J Pharm Res 2014;3:1223-33.

14. Kumar DA, Subbaiah MV, Purushothaman M. Evaluation of adverse drug reactions in a tertiary care teaching hospital. World J Pharm Pharm Sci 2015;4:1192-202.

15. Nahar N, Karim A, Paul PC, Khan TH. Response of reporting adverse drug reactions among medical practitioners. Bangladesh Med J 2011;40:13-8.

16. Srinivasan R, Ramya G. Adverse drug reaction- Causality assessment. Int J Res Pharm Pharm Pract 2011;1:606-12.

17. Kumar L. Pharmacovigilance/reporting adverse effect reactions: An approach to enhance health surveillance and extending market share by minimizing the chances of drug withdrawal. Int J Pharm Pharm Sci 2015;7:1-7. 